\title{
DEVELOPMENT OF EARTHQUAKE DEMONSTRATION TOOL AS A PHYSICS SCIENCE LEARNING MEDIA
}

\author{
Wuly Gunawan ${ }^{* 1)}$, M. Nor ${ }^{2)}$, Hendar Sudrajad ${ }^{3)}$ \\ ${ }^{1,2,3)}$ Physics Education, University of Riau \\ e-mail: ${ }^{* 1)}$ wulygunawan@gmail.com \\ m.nor@lecturer.unri.ac.id
}

\begin{abstract}
The creation of interactive learning activities can be influenced by the availability of media and learning resources as a useful tool in teaching and learning activities. The effectiveness of students' absorption of difficult and complicated learning materials can be achieved with the help of the demonstration tool as a media. The purpose of this research is to produce an earthquake demonstration tool, as a valid learning media for use in the learning process of physics in junior high schools. This development research uses the $R \& D$ method which was adapted from Nieveen \& Folmer with three-phase, namely: preliminary research, development or prototyping phase, and the formative evaluation within the development stage. The evaluation of the validation of the media uses the instrument of validation of the earthquake demonstration tool with 5 indicators and the assessment of validation of the guidebook with 4 indicators. The results of the design of the media obtained the validation score for the earthquake demonstration tool with a score of 4.5 where a very valid category and the handbook obtained a validation score of 4.4 with a very valid category. Based on the results of this research, an earthquake demonstration tool had been successfully made and a guidebook for its use as a physics science learning media is valid and suitable for use in junior high schools.
\end{abstract}

Keywords: earthquake, physics science learning media, demonstration tool. 


\title{
PENGEMBANGAN ALAT PERAGA GEMPA BUMI SEBAGAI MEDIA PEMBELAJARAN IPA FISIKA
}

\author{
Wuly Gunawan ${ }^{* 1}$, M Nor $^{2}$, Hendar Sudrajad ${ }^{3)}$ \\ ${ }^{1,2,3)}$ Pendidikan Fisika, Universitas Riau
}

\begin{abstract}
Abstrak
Terciptanya kegiatan pembelajaran yang interaktif dapat dipengaruhi oleh tersedianya media dan sumber belajar sebagai alat bantu yang berguna dalam kegiatan belajar mengajar. Keefektifan daya serap siswa terhadap bahan pelajaran yang sukar dan rumit, dapat dicapai dengan bantuan media sebagai alat bantu.Tujuan penelitian pengembangan ini untuk menghasilkan alat peraga gempa bumi, sebagai media pembelajaran yang valid untuk digunakan dalam proses pembelajaran IPA fisika di SMP. Penelitian pengembangan ini menggunakan metode $\mathrm{R} \& \mathrm{D}$ yang diadaptasi dari Nieveen \& Folmer dengan tiga tahapan yaitu tahap: preliminary research, development or prototyping phase, dan tahap formative evaluation within development. Penilaian validasi alat peraga gempa bumi ini menggunakan instrumen penilaian validasi alat peraga gempa bumi dengan 5 indikator dan penilaian validasi buku panduan dengan 4 indikator. Hasil perancangan media didapatkan hasil yaitu skor validasi untuk alat peraga gempa bumi diperoleh skor 4,5 dengan kategori sangat valid dan buku panduan alat peraga diperoleh skor validasi 4,4 dengan kategori sangat valid. Berdasarkan hasil penelitian ini, maka telah berhasil dibuat sebuah alat peraga gempa bumi dan buku panduan penggunaannya sebagai media pembelajaran IPA fisika yang valid dan layak digunakan di sekolah menengah pertama.
\end{abstract}

Kata Kunci: gempa bumi, media pembelajaran IPA fisika, alat peraga.

\section{Pendahuluan}

Rahayuningsih \& Dwiyanto (2005) mengungkapkan bahwa dalam pendidikan fisika, siswa diarahkan untuk mencari tahu dan berbuat sesuatu sehingga dapat memperoleh pemahaman yang lebih mendalam tentang alam sekitar. Dengan demikian, pembelajaran fisika harus dikembangkan berdasarkan basis kegiatan interaktif dan partisipatif yang memotivasi siswa dalam mencapai hasil belajar yang baik.

Menurut Surya (2003) tingkat perkembangan intelektual siswa SMP kelas VII berada pada tahap operasional konkrit, dimana anak sudah matang untuk menggunakan pemikiran logika atau operasi, tetapi hanya untuk objek fisik yang ada saat ini. Dalam tahap ini, anak telah hilang kecenderungan terhadap animism dan articialisme. Egosentrisnya berkurang dan kemampuannya dalam tugas-tugas konservasi menjadi lebih baik. Namun, tanpa objek fisik di hadapan mereka, anak-anak pada tahap operasional konkrit masih mengalami kesulitan besar dalam menyelesaikan tugas-tugas logika.

Terciptanya kegiatan pembelajaran yang interaktif dapat dipengaruhi oleh penggunaan media dan sumber belajar sebagai alat bantu yang berguna dalam kegiatan belajar mengajar. Media yang digunakan dapat mewakili sesuatu yang tidak dapat disampaikan oleh guru melalui kata-kata. Keefektifan daya serap siswa terhadap bahan pelajaran yang sulit dan rumit dapat dicapai dengan bantuan media sebagai alat bantu. Bahkan alat bantu diakui dapat melahirkan umpan balik yang baik dari siswa. Dengan memanfaatkan taktik alat bantu yang akseptable, guru dapat meningkatkan semangat belajar peserta didik (Syaiful Bahri Djamarah \& Zain, 2005).

Adanya media pada proses pembelajaran mempunyai posisi cukup penting dalam pendidikan. Dimyati \& Mudjiono (2006) menyatakan bahwa media dapat dijadikan perantara untuk menyampaikan materi yang masih abstrak dan dianggap rumit. Tidak adanya media pembelajaran, dapat mengakibat kan motivasi belajar siswa terhadap mata pelajaran seperti IPA rendah, sehingga membuat siswa mudah merasa bosan dan jenuh (Huda, 2014). Siswa yang memiliki motivasi rendah dalam proses pembelajaran menunjukkan sikap enggan mengikuti proses pembelajaran yang berdampak pada siswa yang menjadi pasif di kelas. 
Salah satu media pembelajaran yang dapat digunakan pada pembelajaran fisika adalah tersedianya alat peraga (alat demonstrasi). Dalam proses belajar mengajar alat peraga dipergunakan dengan tujuan membantu agar proses belajar peserta lebih efektif dan efisien. Kegiatan peragaan dapat di representasikan sebagai salah satu cara agar seseorang memperoleh ilmu pengetahuan. National Training Laboratories dalam Farida Huriawati \& Andista Candra (2016) menemukan fakta, bahwa pelajar hanya dapat mengingat materi pelajaran sebanyak 5\% sampai $10 \%$ dari yang mereka baca di dalam buku bacaan, tetapi mereka dapat mengingat hingga $80 \%$ dari yang telah mereka alami/kerjakan.

Kenyataanya sekarang kebanyakan guru dalam proses penyampaian konsep kepada siswa, cenderung hanya menyampaikan konsep dalam bentuk teori. Selama ini pembelajaran yang berlangsung di sekolah cenderung menunjukkan Guru lebih banyak berceramah, media belum dimanfaatkan secara optimal, pengelolaan belajar masih klasikal dan kegiatan belajar kurang bervariasi (Syaiful Sagala, 2014). Dengan pembelajaran seperti itu tentunya membuat siswa tidak dapat berperan aktif dalam proses pembelajaran, serta siswa tidak terlalu memahami tentang konsep yang disampaikan, sedangkan pada kurikulum 2013 proses pembelajaran IPA haruslah menggunakan pendekatan saintifik untuk semua mata pelajaran. Artinya semua siswa harus ikut berperan aktif dalam proses pembelajaran baik itu mengamati, memberi pertanyaan, mengumpulkan data, melakukan penalaran, serta penyajikan hasil melalui pemafaatan berbagai sumber belajar. Dengan kata lain, pada kurikulum 2013 menuntun siswa mencari tahu bukan diberi tahu (Permendiknas, 2013).

Deassy \& Wahono (2017) mengatakan bahwa siswa lebih suka pembelajaran dengan menggunakan media serta dilibatkan dalam penggunaan media sebagai rangsangan belajar bagi mereka yang memperoleh hasil $73 \%$ siswa menyatakan termotivasi memperlajari IPA dengan menggunakan media pembelajaran yang sesuai dan lengkap melalui pengisian angket pra-penelitian.

Hasil wawancara yang dilakukan peneliti via telewicara dengan salah seorang guru IPA di SMP Negeri 14 Pekanbaru mendapatkan temuan, bahwa pembelajaran IPA yang dilakukan di sekolah tersebut masih dominan menggunakan metode ceramah dan belum banyak menggunakan media pembelajaran khususnya pada sub materi pergerakan lempeng. Kurangnya media pembelajaran juga mempengaruhi motivasi dan hasil belajar siswa kelas VII pada materi Struktur Bumi dan Dinamikanya. Kajian pendahuluan mendapati hasil wawancara bahwa, guru sangat memerlukan media pembelajaran fisik dalam menunjang pembelajaran IPA SMP, khusus nya pada materi struktur bumi dan dinamikanya.

Manfaat media dalam pembelajaran pada umumnya dapat memperlancar interaksi guru dan siswa, dengan maksud membantu siswa agar belajar secara optimal. Secara terperinci manfaat media pembelajaran antara lain: dengan media penyampaian materi pembelajaran dapat diseragamkan, proses pembelajaran menjadi lebih menarik, proses pembelajaran menjadi lebih interaktif, menghemat waktu belajar, kualitas belajar siswa dapat ditingkatkan, serta sikap positif siswa terhadap proses belajar dapat ditingkatkan (Kemp \& Dayton, 1985). Jadi dengan adanya media, guru tidak perlu mengulang-ulang penjelasan dan mengurangi penjelasan verbal (lisan), sehingga guru dapat memberikan perhatian lebih banyak kepada aspek pemberian motivasi, perhatian, dan bimbingan yang dapat berdampakpositif terhadap hasil belajar siswa.

\section{Bahan dan Metode}

Penelitian pengembangan alat peraga gempa bumi dilakukan di Laboratorium Pengembangan Media Pembelajaran Fisika Program Studi Pendidikan Fisika, Fakultas Keguruan dan Ilmu Pendidikan, Universitas Riau. Penelitian pengembangan alat peraga gempa bumi sebagai media pembelajaran IPA fisika SMP dilakukan pada semester genap tahun 2019.

Penelitian pengembangan alat peraga gempa bumi IPA fisika SMP ini merupakan penelitian yang melewati beberapa tahap, sehingga dihasilkan suatu produk yang valid. 


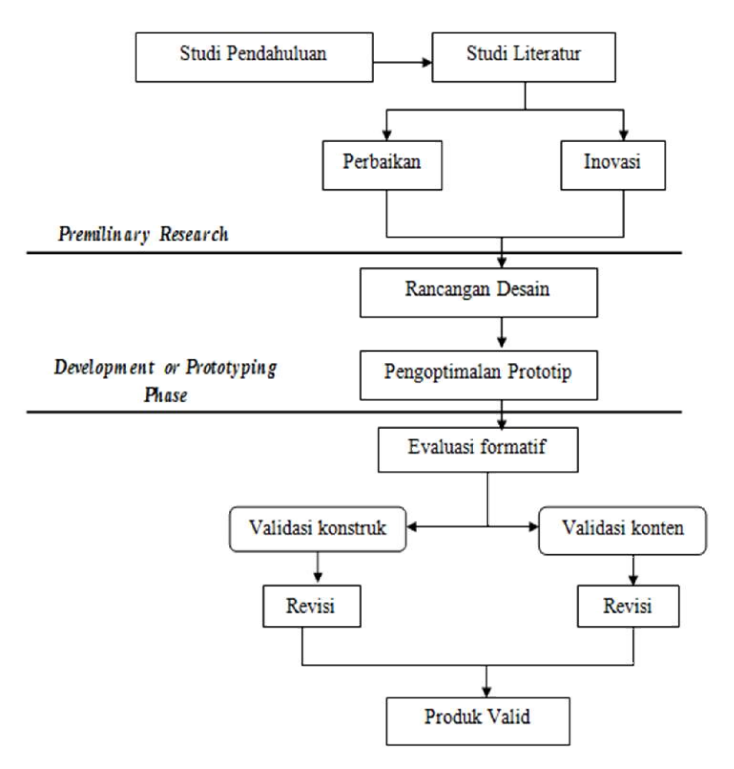

Gambar 1. Alur pengembangan alat peraga gempa bumi (Nieveen \& Folmer, 2011).

Peneliti menggunakan metode penelitian dan pengembangan atau Research and Development (R\&D) yang diadaptasi dari Nieveen \& Folmer (2011). Penelitian pengembangan ini didasarkan pada masalah di lapangan dan dalam pelaksanaannya melibatkan partisipan, peneliti, ahli, dan stakeholder lainnya. Tahaptahap penelitian $\mathrm{R} \& \mathrm{D}$ yang dilakukan meliputi tiga tahap yaitu: 1). preliminary research, 2). development or prototyping phase, 3). formative evaluation within development. Tahap-tahap penelitian pengembangan alat peraga gempa bumi ditunjukkan pada Gambar 1. Berdasarkan Gambar 1. penelitian pengembangan alat peraga gempa bumi diuraikan sebagai berikut.

a. Penelitian pendahuluan (premilinary research)

Pada studi pendahuluan, mengkombinasikan antara potensi dan masalah dengan pengumpulan data sebagai tahap awal dari penelitian. Studi pendahuluan dilakukan dengan cara mencari informasi melalui studi literatur tentang kesulitan belajar siswa untuk mempelajari IPA fisika pada umumya dan mempelajari materi IPA gempa bumi pada khusunya.

b. Tahap pengembangan dan pembuatan (development or prototyping phase)

Setelah dilakukan studi pendahuluan untuk menemukan permasalahan dalam pembelajaran IPA fisika SMP pada materi gempa bumi, maka tahap selanjutnya adalah membuat desain dan prototipe alat peraga untuk membantu menyelesaikan permasalahan pada proses pembelajaran pada materi gempa bumi. Tahap pengembangan dan pembuatan melalui beberapa tahapan, yaitu tahap perancangan desain alat peraga dan tahap pembuatan prototipe.

c. Evaluasi formatif

Tahap evaluasi alat peraga dan buku panduan alat peraga, diuji kevalidannya. Tahapan evaluasi formatif yang dilakukan untuk menguji kevalidan alat peraga dan buku panduan alat peraga yang dibuat melalui uji ahli (expert review). Uji ahli dilakukan untuk melihat kesesuaian alat peraga dan buku panduan dengan materi pembelajaran dan menilai secara detail halhal yang berkaitan dengan teknis alat peraga yang dirancang (Tessmer, 2005). Luaran dari evaluasi formatif adalah didapatkannya gambaran awal dari alat peraga dan buku panduan terhadap butirbutir validasi yang telah diajukan. Indikator validasi alat peraga terdiri dari 5 indikator yaitu fungsi perangkat, unsur pembelajaran, kemudahan, estetika dan konstruksi, keamanan kerja. Selanjutnya validasi panduan meliputi: ketepatan isi, kelayakan penyajian, bahasa dan tampilan. Penilaian setiap indikator menggunakan skala liket 1 sampai 5 disertai dengan pengkategorian dari tidak valid sampai sangat valid.

\section{Hasil dan Pembahasan}

\section{Preliminary Research}

Melalui tahapan ini dilakukan studi literatur dari berbagai sumber buku maupun jurnal untuk mengumpulkan permasalahan yang ada pada pembelajaran terkait. Selanjutnya dilakukan wawancara terhadap guru Sekolah Menengah Pertama (SMP) dan didapatkan penjelasan terhadap kurangnya alat peraga pada materi pergerakan lempeng dan gempa bumi. Hal ini sesuai dengan kajian analisis keperluan M. Rahmad et al. (2019) terkait diperlukannya media alat peraga dalam pembelajaran pencemaran lingkungan di SMP 


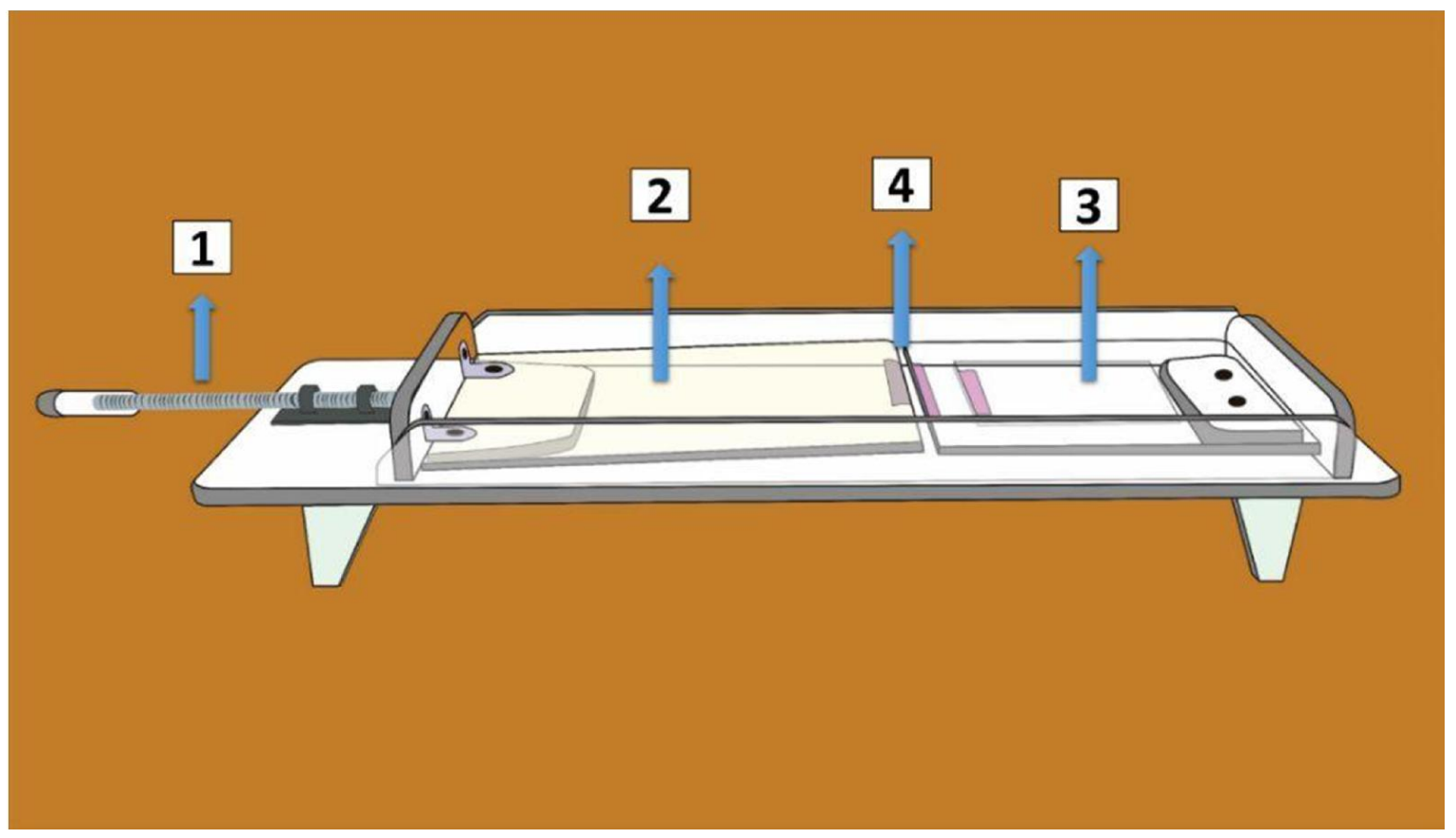

Gambar 2. Rancang bangun alat peraga gempa bumi.

yang mudah digunakan dan bersifat portabel dalam pengujian kualitas udara untuk mengetahui tingkat pencemaran yang terjadi di lingkungan.

\section{Development or Ptototyping Phase}

Pada tahapan ini dilakukan perancangan desain alat peraga gempa bumi seperti ditunjukkan pada Gambar 2. Adapun deskripsi dari rancang bangun alat peraga gempa bumi berdasarkan kode angka adalah sebagai berikut.

1) Ragum pemutar

2) Ragum pemutar digunakan sebagai penggerak dari lempeng samudra yang merupakan representasi dari energi yang menggerakkan lempeng samudra.

3) Miniatur lempeng samudra

4) Miniatur lempeng samudra digunakan untuk menggambarkan lempeng samudra pada alat peraga.

5) Miniatur lempeng benua

6) Miniatur lempeng benua digunakan untuk menggambarkan lempeng benua pada alat peraga.

7) Akrilik pengait
Akrilik pengait digunakan untuk memunculkan bunyi letupan sebagai indikasi terjadinya gempa bumi.

Pembuatan desain alat peraga gempa bumi telah dilakukan dengan membuat sesuai dengan rancangan dan telah melawati beberapa tahapan revisi. Perangkat alat peraga yang diperoleh dari penelitian ini terdiri dari:

a. Alat peraga gempa bumi.

Alat ini merupakan miniatur dari lempeng samudra dan lempeng benua yang bergerak secara konvergen. Energi dalam menggerak kan lempeng disimulasikan menggunakan ragum pemutar untuk mendorong lempeng samudra. Alat peraga ini bertujuan menggambarkan fenomena gempa bumi dengan memodelkan lempeng yang bertabrakan menggunakan bahan akrilik. Saat kedua lempeng bertabrakan, maka terjadi akumulasi tekanan yang terkumpul pada akrilik, dan saat energi yang diberikan terlalu besar, maka lempeng akan bergerak dan menghasilkan energi yang dapat diamati dari pegas yang bergoyang. Prototipe alat peraga dapat dilihat pada Gambar 3 . 


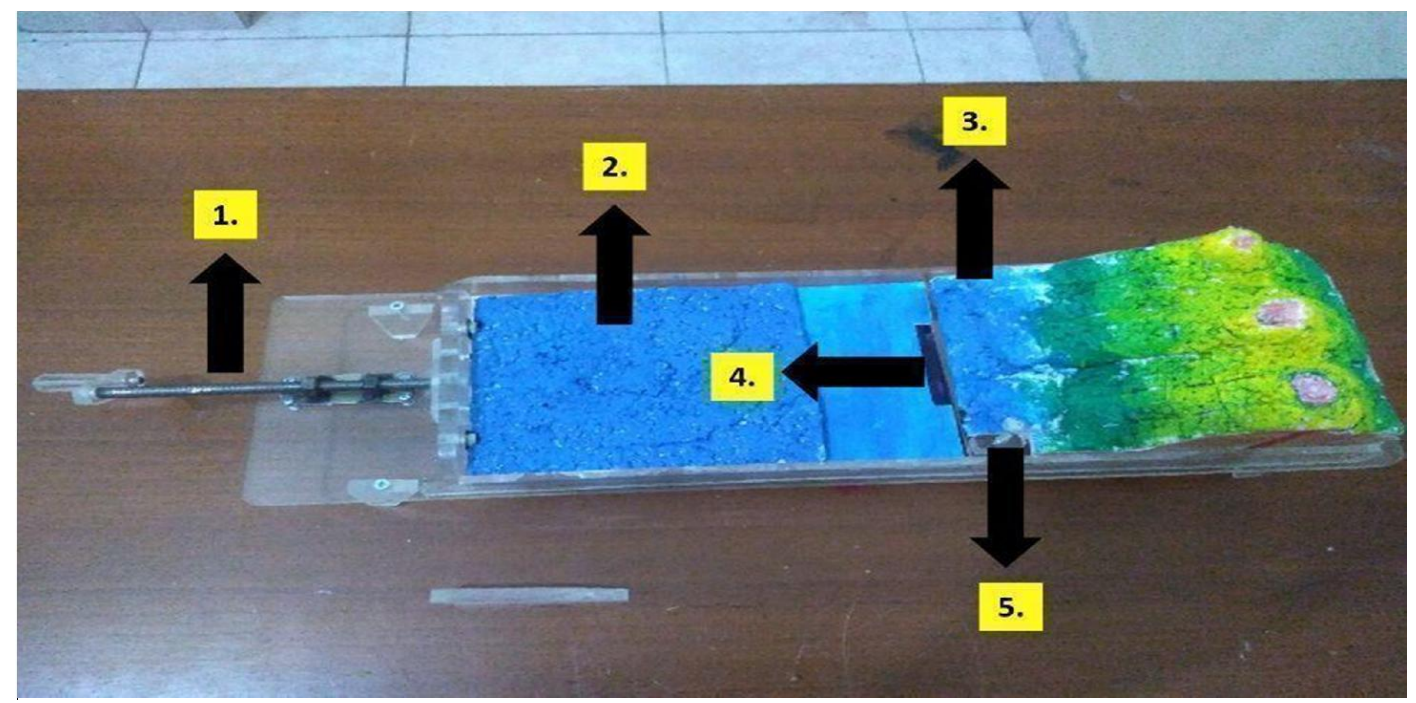

Gambar 3. Alat peraga gempa bumi.

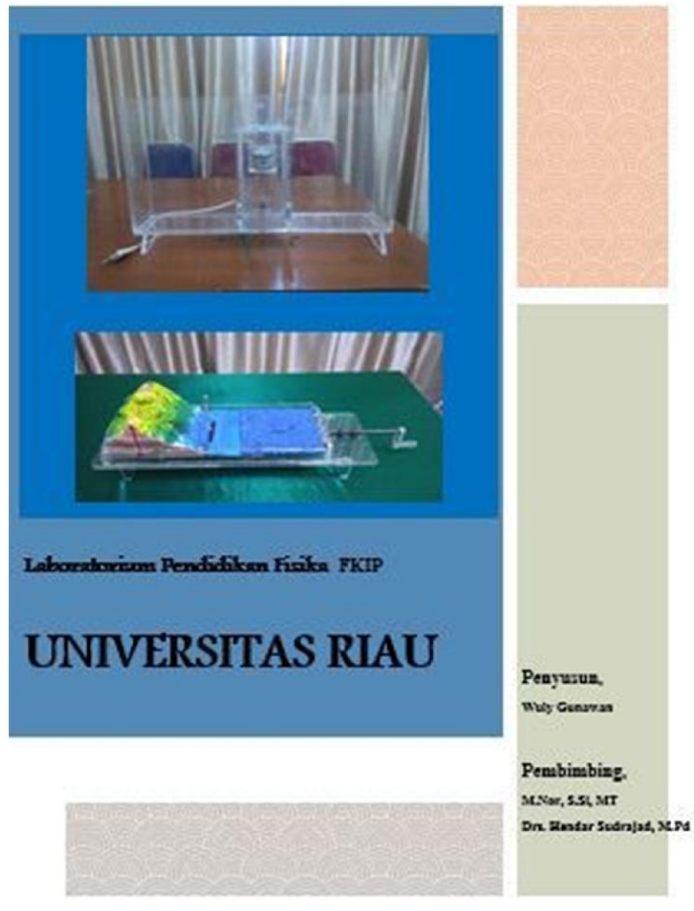

Gambar 4. Buku panduan alat peraga gempa bumi.

Adapun deskripsi dari prototipe alat peraga gempa bumi adalah sebagai berikut: 1). Ragum pemutar sesuai desain alat untuk digunakan sebagai penggerak lempeng samudra, 2). Miniatur lempeng samudra sesuai desain. Bagian ini digunakan untuk menggambarkan lempeng samudra pada alat peraga,
3). Miniatur lempeng benua sesuai desain bagian ini untuk menggambarkan lempeng benua pada alat peraga, 4). Akrilik pengait juga sesuai desain digunakan untuk memunculkan bunyi letupan sebagai indikasi terjadinya gempa bumi, 5). Miniatur tower desain tambahan yang digunakan untuk menunjukkan adanya energi yang dihasilkan dari gesekan antar miniatur antar lempeng. Selain alat peraga juga dilengkapi buku panduan penggunaan bagi memudahkan pengguna dalam menggunakan alat peraga yang di rancang sebagaimana pada Gambar 4.

Buku panduan berfungsi sebagai panduan penggunaan dalam melakukan kegiatan peraga yang telah dibuat. Buku panduan penggunaan alat peraga gempa bumi terdiri atas dua bagian, yang meliputi:

a. Bagian pertama: pendahuluan

Bagian ini berisikan tentang latar belakang alat peraga, tujuan alat peraga dan pengenalan alat peraga.

b. Bagian kedua: cara pengoperasikan alat peraga

Bagian ini berisikan tentang cara mengoperasikan alat peraga. Pada bagian ini terdapat panduan alat peraga gempa bumi.

c. Bagian ketiga: Lembar Kerja Peserta Didik. Bagian ini berisikan lembar kerja peserta didik atau siswa yang digunakan sebagai perangkat yang menunjang pembelajaran 
dalam proses mengamati gejala gempa bumi yang diperagakan.

d. Bagian keempat: cara perawatan

Bagian ini berisikan mengenai tata cara membawa dan merawat alat peraga, agar dapat bertahan lama dan tidak terjadi kerusakan setelah digunakan.

Setelah alat peraga siap dibuat dan diujicoba keberfungsiannya, maka dilakukan validasi kepada tiga orang dosen ahli dan dua orang guru IPA fisika. Validasi yang dilakukan bertujuan untuk mengetahui apakah perangkat peraga sudah layak untuk digunakan atau belum.

\section{Formative Evaluation Within Development}

Adapun hasil penilaian validasi alat peraga dan buku panduan oleh validator dapat dilihat pada Tabel 1.

Tabel 1. Hasil validasi alat peraga gempa bumi

\begin{tabular}{|c|c|c|c|}
\hline No & Indikator & Rata-rata & Kategori \\
\hline 1 & $\begin{array}{l}\text { Fungsi } \\
\text { perangkat }\end{array}$ & 4,4 & SV \\
\hline 2 & $\begin{array}{l}\text { Unsur } \\
\text { pembelajaran }\end{array}$ & 4,5 & SV \\
\hline 3 & Kemudahan & 4,5 & SV \\
\hline 4 & $\begin{array}{l}\text { Estetika dan } \\
\text { konstruksi }\end{array}$ & 4,3 & SV \\
\hline 5 & $\begin{array}{l}\text { Keamanan } \\
\text { kerja }\end{array}$ & 4,7 & SV \\
\hline \multicolumn{2}{|c|}{ Rata-rata Indikator } & 4,5 & SV \\
\hline
\end{tabular}

Ket: SV= Sangat Valid.

Dari data validasi Tabel 1. didapatkan hasil, bahwa alat peraga gempa bumi mendapatkan skor rata-rata validasi sebesar 4,5 dengan kategori sangat valid. Hal ini menunjukkan alat peraga yang telah dirancang sudah valid dan layak digunakan sebagai media pembelajaran gejala gempa bumi. Sebelum sebuah media alat peraga digunakan harus diuji kevalidannya agar tidak mengakibatkan misskonsepsi ketika digunakan dalam pembelajaran. Sesuai dengan kajian Zulirfan et al., (2019) yang telah mendesain kit take-home experiment cahaya dan optik sebagai media pembelajaran sains siswa SMP yang telah diuji kevalidan dan kepraktisannya. Dengan demikian alat peraga gempa bumi ini dapat dilanjutkan pengujian kelayakannya melalui uji praktikalitas dan uji penggunaan dalam skala luas. Selanjutnya untuk kemudahan penggunaan alat peraga, maka disedikan buku panduan penggunaan yang sudah divalidasi oleh tim ahli dan pengguna, yang ditunjukkan pada Tabel 2.

Tabel 2. Hasil validasi buku panduan alat peraga gempa bumi

\begin{tabular}{|c|c|c|c|}
\hline No & Indikator & Rata-rata & Kategori \\
\hline 1 & Ketepatan isi & 4,2 & SV \\
\hline 2 & $\begin{array}{l}\text { Kelayakan } \\
\text { penyajian }\end{array}$ & 4,3 & SV \\
\hline 3 & $\begin{array}{l}\text { Kelayakan } \\
\text { bahasa }\end{array}$ & 4,4 & SV \\
\hline 4 & $\begin{array}{l}\text { Kelayakan } \\
\text { tampilan }\end{array}$ & 4,6 & SV \\
\hline
\end{tabular}

Ket: SV= Sangat Valid.

Hasil uji validasi buku panduan alat peraga gempa bumi mendapatkan skor ratarata validasi 4,4 dengan kategori sangat valid, sehingga buku panduan ini merupakan sumber bantuan yang diperlukan dalam menggunakan alat peraga gempa bumi, untuk menghindari terjadinya miskonsepsi atau kesalahan penggunanan media alat peraga gempa bumi. Dengan dihasilkannya prototipe alat peraga gempa bubumi diserta buku panduan yang sudah diuji keberfingsian dan kevalidannya, maka perangkat alat peraga gempa bumi yang telah dirancang dinyatakan valid dan layak digunakan sebagai media pembelajaran. Alat ini masih dalam batas prototipe, sehingga dimungkinkan masih diperlukan penyempurnaan alat dan iji kepraktisan melalui uji skala kecil atau dalam skala luas (secara klasikal) di sekolah menengah pertama.

\section{Kesimpulan dan Saran}

Berdasarkan hasil penelitian disimpulkan sebagai berikut:

1. Prototipe alat peraga gempa bumi telah berhasil di rancang dan dinyatakan layak sebagai media pembelajaran dengan skor validasi rata-rata sebesar 4,5 dengan kategori sangat valid.

2. Buku panduan alat peraga gempa bumi dinyatakan layak sebagai media pembelajaran dengan skor validasi rata-rata sebesar 4,4 dengan kategori sangat valid. 
Berdasarkan perolehan skor validasi secara keseluruhan, maka alat peraga gempa bumi serta buku panduan penggunaannya dinyatakan valid dan layak digunakan sebagai media pembelajaran fisika.

Perancangan alat peraga gemba bumi yang telah dirancang dapat dilanjutkan uji kepraktisannya dalam skala kecil atau skala luas. Dapat dikembangkan alat peraga gempa bumi untuk penyempurnaan dengan menambahkan unsur seperti patahan pada lempeng yang bertumbukan.

\section{Daftar Pustaka}

Deassy \& Wahono. (2017). Pengembangan kit struktur bumi dan simulasi gempa sebagai media pembelajaran untuk meningkatkan keterampilan berpikir kritis siswa kelas VII. E-Journal Unesa, 5(2), 83-91. www.jurnalmahasiswa.unesa.ac.id (diakses 11 April 2019).

Dimayati \& Mudjiono. (2006). Belajar dan Pembelajaran. Jakarta: PT Rineke Cipta.

Farida Huriawati \& Andista Candra. (2016). Pengembangan odd "osilator digital detector" sebagai alat peraga praktikum gerak harmonik sederhana. Jurnal Inovasi dan Pembelajaran Fisika. ISSN: 23557109. FKIP Universitas Sriwijaya. Sumatra Selatan.

Huda, M. (2014). Model-model Pengajaran dan Pembeleajaran. Yogyakarta: Pustaka Pelajar.

Kemp, J.E \& Dayton, D.K. (1985). Planning and Producing Instructional Media. New
York: Cambidge Harper \& Row Publisher.

M. Rahmad, Dina Syaflita, M. Nor, \& Metty Susanti. (2019). Needs Analysis of Air Quality Detection Tool in Project Based Learning. J. Phys.: Conf. Ser. 1351 012066. IOP Publishing, doi:10.1088/ 1742-6596/1351/1/012066.

Nieveen, N., \& Folmer, E. (2011). Formative evaluation in educational design research. dalam T. Plomp \& Nieveen, (Eds), An Introduction to Educational Design Research. The-Netherlands: SLO.

Permendiknas. (2013). Permendiknas nomor 69 tahun 2013 tentang kerangka dasar dan struktur kurikulum sekolah menengah. Jakarta: Departemen Pendidikan Nasional.

Rahayuningsih \& Dwiyanto. (2005). Pembelajaran di Laboratorium. Yogyakarta: Pusat Pengembangan Pendidikan UGM.

Surya, Mohd. (2003). Psikologi Pembelajaran dan Pengajaran, Cet. II. Bandung: Yayasan Bhakti Winaya.

Syaiful Bahri, Djamarah \& Zain. (2005). Guru dan Anak Didik dalam Interaksi Anak Didik. Jakarta: Rineka Cipta.

Syaiful Sagala. (2014). Konsep dan makna pembelajaran. Bandung: Alfabeta.

Tessmer, Martin. (2005). Planning and Conducting Formative Evaluations: Improving the Quality of Education and Training. London: Routledge.

Zulirfan, Zanaton, H.I., \& Tamby Subahan, M.M. (2017). Pengembangan Kit TakeHome Experiment Cahaya Dan Optik Sebagai Media Pembelajaran Sains Siswa Sltp. Jurnal Geliga Sains, 5(1), 1-7. 